\title{
TICTAC
}

\section{Information and Communication Technologies for Augmentative Communication Boards}

\author{
Fátima Ma García Doval \\ CEE Manuel López Navalón \\ Consellería de Educación e O.U. \\ Santiago de Compostela, Spain \\ fmgdoval@edu.xunta.es
}

\author{
José Ma Pousada Carballo \\ Deepto.de Ingeniería Telemática \\ Universidad de Vigo \\ Vigo, Spain \\ chema@uvigo.es
}

\author{
José Manuel Vez Jeremías \\ Instituto de Ciencias de la Educación \\ Universidad de Santiago de Compostela \\ Santiago de Compostela, Spain \\ josemanuel.vez@usc.es
}

\begin{abstract}
Providing a communication aid is a complex issue which requires a deep insight on the theoretical backgrounds, the technological basis and, specially, the problems faced in bringing together the expectations and needs of users, teachers, speech therapists, families... and the perspectives and knowledge of linguists, teachers, engineers and speech pathologists. In this ongoing project we intend to develop and implement helpful tools for students with communicative impairment by means of communication boards based on icons, pictures or conventional characters.
\end{abstract}

Keywords-Augmentative and Alternative Communication, Communication Boards, Special Needs, Accessibility

\section{INTRODUCTION}

The development of a human being depends a great deal on the ability to communicate. Not only social aspects are involved, but also those related to psychological stability and cognitive development.

History is full of examples of great people who made their way through communication difficulties. Hellen Keller, deafblind was the first person gaining a Bachelor Degree of Arts, a great author. Political activist and lecturer, she would have been lost without Anne Sullivan's determination.

In 1995 Jean-Dominique Bauby, editor-in-chief of French Elle magazine suffered a rare kind of stroke who left him in a locked-in syndrome (a condition in which a perfectly agile mind is trapped in a useless body). He could not walk, eat or even breath. All he could do was blinking his left eye. He dictated an entire book on his experiences by having the alphabet told and blinking to select a letter. His story inspired the film Le Scaphandre et le papillon (The Diving Bell and the Butterfly).

It is also inevitable to mention Stephen Hawking, whose colossal efforts allow us to enjoy the ideas and theories of one of the most influential physicist nowadays.

This colossal efforts are made at an outstanding personal cost, and here is where technological aids may provide that extra-help needed to forget about communication methods and to focus on communicative content.

Digital aids have proven helpful in getting the message from those unable to speak or even write through conventional methods. If we do not help every student to effectively communicate and develop their minds to the maximum we would never know how many great minds are we leaving behind, locked in dysfunctional bodies.

Readiness as a key aspect in a communicative act. It is important, not only to provide with an effective way of communication, but it also has to be a quick one. This way we allow the user to keep pace of a conversation. Otherwise the hole speech would result in a monologue.

Personal assistants dictating the alphabet have been replace by scanning switch activated keyboards. The former went through all the available characters following, in most cases, the conventional alphabetic order. As for the latter, the standard is the QWERTY display. None of the sequences has been set with a scanning approach in mind.

This project is aimed to explore and optimize the scanning sequence implementing a frequency based sequence (recently used by communication assistants), thus reducing time waste and allowing more fluent communicative exchanges.

We will set the basis of augmentative and alternative communication to analyze conventional communication boards used with students and adults. The TICTAC approach will be presented to have a better idea of the whole communication strategy behind the project. Finally we will go through the main features of TICTAC virtual keyboard.

As it is a work in process final results are yet to come, but there are indicators showing a lot of people may find this keyboard useful, making a difference in their everyday lifes.

\section{AugMentative AND Alternative COMMUNICATION}

\section{A. Defining AAC Systems}

According to the American Speech-Language-Hearing Association (ASHA): 
Augmentative and alternative communication (AAC) includes all forms of communication (other than oral speech) that are used to express thoughts, needs, wants, and ideas. We all use $A A C$ when we make facial expressions or gestures, use symbols or pictures, or write.

People with severe speech or language problems rely on $A A C$ to supplement existing speech or replace speech that is not functional. Special augmentative aids, such as picture and symbol communication boards and electronic devices, are available to help people express themselves. This may increase social interaction, school performance, and feelings of self-worth [1].

There are many types of AAC but they tend to fall into two main groups:

- Unaided communication systems, such as gestures, sign language or traditional communication boards. They do not provide voice output and no electronic hardware is involved.

- Aided communication systems which are the trend nowadays:

[...] electronic devices that may or may not provide some type of voice output. Devices that provide voice output are called speech generating devices. These devices can display letters, words, and phrases, or a variety of symbols, to allow the user to construct messages. Messages can be spoken electronically and/or printed on a visual display or strip of paper. Many of them can connect to a computer for written communication. Some of them can be programmed to output different spoken languages [1].

\section{B. AAC User}

The first difficulty we come across with when we try to identify the potential user is the lack of patterns in this population. They come from all age and socio-economic groups; appear in all backgrounds, have all sort of health conditions and show different levels of communication performance.

The ASHA gave us the most commonly used definition of this population.

Individual with severe communication disorders are those who may benefit from AAC -those for whom gestural, speech, and/or written communication is temporarily or permanently inadequate to meet all of their communication needs. For those individuals, hearing impairment is not the primary cause for the communication impairment. Although some individuals may be able to produce a limited amount of speech, it is inadequate to meet their varied communication needs. Numerous terms that were initially used in the field but are rarely mentioned include speechless, nonoral, nonvocal, nonverbal, an aphonic [2].

A number of studies [3] suggest that 8 to 12 people per 1.000 may experience severe communication impairments that require $\mathrm{AAC}$.

\section{Ethiology}

We must assume there is no typical AAC user, even given the same primary cause for the lack of communicative exchange.

Nevertheless disabling conditions that may require AAC have been categorized into four types [4]: congenital conditions, acquired disabilities, progressive neurological diseases and temporary conditions. Cerebral palsy, mental retardation or autism are examples of congenital conditions. Acquired impairments that may lead to the use of AAC include traumatic brain injury, cerebral vascular accident, laryngectomy or glossectomy. There is a number of progressive neurological diseases with an impact on communication such as multiple sclerosis or Parkinson's disease. Finally, we must consider those cases in which the restriction in communication is temporal (e.g. intubation or severe facial burns).

\section{COMMUNICATION BOARDS}

A communication board is a technical help for AAC users consisting in a surface where the communication facilitator displays a variety of icons, symbols, letters, words... for the person to point, stare at, or select by any means available (such as automatic scrolling for scanning).

\section{A. Traditional}

These are hand-made custom boards. The facilitator decides on the concepts included and their display. Then, he places them on the board (a piece of wood, cardboard, plastic...) either manually or setting the display with the aid of a computer program such as Boardmaker [5] and printing the complete board to stick it to an appropriate surface.

These, though very popular both in primary and secondary school, highly limit the communicative competence of the individual and basically avoid any possibility of a conversation.

\section{B. Electronic}

We include here most commercial communicators. Some of them barely differ from the traditional ones except for the fact that the selection triggers an action (generation of artificial voice, playing an audio file or printing a message on the screen or paper). The level of customization varies considerably among them. Some may be designed from scratch while others are predetermined by default with little room for customization.

Their readiness and the supporting role of the company selling the product to solve eventual problems is to be taken into account.

But a careful cost-benefit study must be carried out from a long-term perspective as they are not so useful with this idea in mind. It also limits considerably the vocabulary available and the structure of the sentences, which becomes more and more important as the studies approach to a university level. 


\section{Digital}

Communication Boards based on digital environments are becoming less scarce. Although most commercial digital boards are simply unaffordable for most families or institutions; the efforts of professionals in bringing together their IT skills with their AAC mastery are laying the foundations of an exciting new way of approaching AAC.

People with severe impairment are especially vulnerable to separation from the mainstream society. Technologies applied to AAC systems may help to bridge that gap [6].

\section{Digital COMMUNICATION BOARD}

In order to help people (particularly students) showing communication impairments, we are currently working on a set of two digital communication boards aiming two radically different problems. Both of them draw the limits of the issue according to the "ability to write" criterion. This ability should be assessed in 'cognitive terms' rather than 'motility terms'.

An cognitively impaired person who is, as a result, unable to read or write needs a communication system capable of easily transmit basic needs and feelings. They do not feel the urge to communicate and just do as they please with a very low tolerance to frustration. They interact with a limited number of people (therapist, teachers, etc), normally trained ad hoc to understand their jargon. In other words we need to focus on simplicity in terms of access, meaning and use: a simple message followed by a quick response. Iconic communication serves this cause effectively.

On the other hand, physically impaired users preserve all the intelligence (average or gifted) and have the need to express themselves in complex ways. They have a better frustration handling and are able to deal with delayed responses. They are also able to enrich their message with a variety of paralinguistic resources. Their social network is wider and may benefit extremely from the use of written language.

\section{A. AAC Systems Board}

The first board has been completely developed as an icon/picture based board intended for AAC Systems in individuals without the ability to acquire a written code. A basic form of A.I. allows it to continually adapt itself to the needs of the user, as well as being proactively adapted by speech therapists and caretakers. It includes built-in functions to improve basic communication skills. It has also been partially implemented and tested by a pilot user.

This board has been already described [7] and will not be discussed here as it is highly improbable for one of its users to reach engineering studies (either vocational or university), given the cognitive impairment associated to the communicative problem. We can not rule it out completely, though as we are discovering interesting capabilities particularly in mathematics an physics in certain individuals, e.g. autistic savants may be unable to read or write but could understand and express complicated formulas and equations given in mathematical notation.

\section{B. Virtual Keyboard}

The second board is being developed and expected to be implemented and tested by pilot users by the second term of this academic year. It is intended for those physically impaired and thus, unable to hand-write or use an adapted keyboard but who are cognitively able to write. It consists of a virtual scanning keyboard optimized using cryptography algorithms activated through any standard or custom-made push-button.

This is, due to its characteristics and features, the communication board most likely to be used by engineering students with special needs, and unable to make use of conventional virtual keyboard; thus, demanding a scanning system to select the different characters and symbols.

Writing through a scanning device is somehow similar to playing scrabble, only here you have an specific message to deliver. Given this situation you would rather get an ' $j$ ' than a ' $\mathrm{w}$ ' when writing in Spanish (or exactly the opposite in English). This approach sets the basis of the virtual keyboard.

Scanning programs like Kanghooru (http://www.xtec.cat/ jlagares/f2kesp.htm) allow setting the optimal computer screen scanning order for each individual case. This type of programs may be used in conjunction with TICTAC keyboard to operate a computer. Bearing this in mind, four 'keys' have been left blank (e.g. launching software).

The keyboard is also able to speak when used with Llegir (http://www.xtec.cat/ jlagares/f2kesp.htm ), a text-to-speach program specifically designed for physically impaired users.

\section{VIRTUAL KEYBOARD ANALISYS}

\section{A. Display}

This board is set as a conventional virtual keyboard, displayed on screen and maximizing the character area to enable students with visual impairment or difficulties in staring at a particular point to go through the board with following the scanning.

There is a number of differences which outstand against the traditional QWERTY keyboard in terms of display:

- All conventional function keys have been removed.

- All symbols have been grouped under the symbol category.

- The upper line is used for the compacting categories: vowels, consonants, capital letter, number, symbol, control, end.

- Vowels come first, they are colored distinctively and ordered within their category according to frequency criterion, this is, the more used the vowel in the language selected, the earlier will be scanned.

- Consonants are the next category, also distinctively colored, and again ordered according to their frequency in the language selected. 
- May turns the letter selected into a Capital Letter. There is no Capitals Lock.

- Numbers are ordered conventionally.

- All symbols available are displayed and have been reduced to the ones which are essential for communication. E.g. we only include closing question and exclamation marks, because those are the ones required in many languages, and enough in Spanish to give the intention implied in the message.

- The .com extension has been included as a facilitator given its importance and prevalence in on-line communications, and its difficulty to be written by scanning.

- $\quad b \_t / b \_p / b \_l$ are accessed through the control button and stand for delete_ everything /delete_word / delete_letter (borrar_todo, borrar_palabra, borrar letra, in spanish) respectively.

\begin{tabular}{|c|c|c|c|c|c|c|}
\hline ta Frovitios & 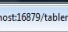 & & & & \multicolumn{2}{|c|}{ Â. } \\
\hline vocal & cons & may & numero & simbolo & control & fin \\
\hline e & a & 0 & $\mathrm{i}$ & u & 0 & 1 \\
\hline 2 & 3 & 4 & 5 & 6 & 7 & 8 \\
\hline 9 & $s$ & $r$ & $\mathrm{n}$ & $d$ & I & C \\
\hline $\mathrm{t}$ & $m$ & $p$ & $b$ & $g$ & $\mathrm{v}$ & $y$ \\
\hline$q u$ & $\mathrm{~h}$ & f & $z$ & $\mathrm{j}$ & $\mathrm{x}$ & W \\
\hline$\tilde{n}$ & $\mathrm{k}$ & - & - & . & , & ? \\
\hline ! & + & * & 1 & $=$ & (Q) &.$c o m$ \\
\hline b_t & b_p & b_l & & & & \\
\hline
\end{tabular}

Figure 1.

Keyboard display

\section{B. Letter frequency}

As we have mentioned earlier, all vowels and consonants have been arranged within the keyboard to follow their frequency order in the language used.

A lot has been discussed [8] on the QWERTY letter distribution but contrary to the urban legend (assuming the display slowed the typist), this was developed according to statistical evidence on letter frequency in English but intended to be use with both hands (ten fingers) at a time. This means it is a very fast display if you can use ten fingers moving over the keyboard. Scanning through a QWERTY keyboard distorts the benefits derived from a careful design. Much of the same applies to following the Latin alphabet on its conventional order.

There are two languages available in this keyboard: Spanish (Castilian) and Galician.

Letter frequency is available for Spanish [9], but it had not been determined for Galician. To confirm the information found for Spanish as well as to establish the letter frequency in Galician, a statistical analysis was run using Make Character (Letter) Frequency Count Software by Sobolsoft, based on long texts (above a million characters)

Nevertheless the frequency of the letters in a language depends a great deal on the type of text used (e.g. a legal text tends to the use of particular verb forms increasing the prevalence of ' $r$ ' or ' $d$ ' or ' $n$ '. That is why, instead of using one single text, the letter frequency has been determined using different texts from a variety of sources. Further field tests need to be done to adjust the order of the letters to everyday use. As practice makes perfect, it is clear that once determined an order, the user should keep it as practice gained increases speed much more than any eventual modification to fit minor statistical differences.

\section{Technical Issues}

This virtual keyboard is a web application. It has been developed in Netbeans 6.5 and the application server will be Sun Glassfish v. 2. The programming language used is Sun Java EE5 with IceFaces framework. This framework applies Ajax (Asynchronous JavaScript + XML) transparently to the programmer. Using this technology we avoid flickers and reloading screens as well as making the program less bandwidth demanding and enhancing the user experience.

\section{Keyboard Access}

To select a character from the keyboard while it is been automatically scanned, the users must provide a click by any means available to their mobility. This could be pressing a push-button, blowing on a microphone or using any other click emulator.

To facilitate learning and adapting the keyboard to users expertise and mobility the scanning speed can be adjust to:

- Very slow: 10 seconds

- Slow: 8 seconds

- $\quad$ Normal: 5 seconds

- $\quad$ Fast: 3 seconds

- Very fast: 2 seconds

These categories have been determined through observation and practice and might be subject to revision. 


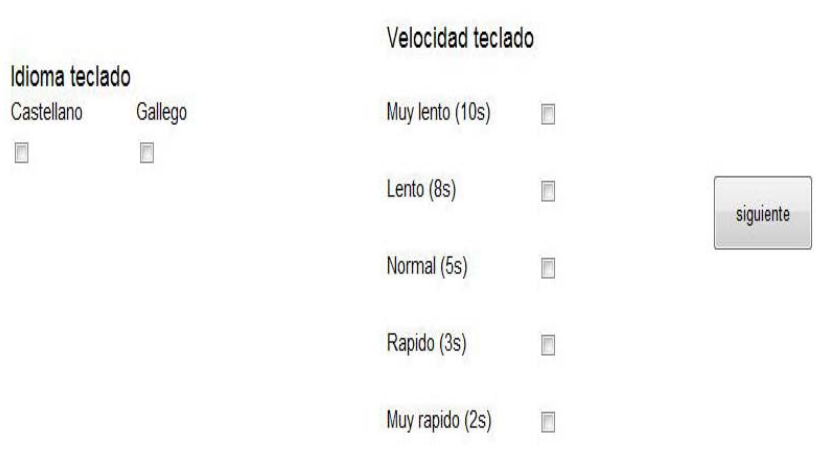

Figure 2. Configuration Screen

\section{ACKNOWLEDGMENT}

We would like to recognize the work of Álvaro Novo Quiza, who made, a useful contribution to communication in severely physical impaired students, but otherwise as smart as a teacher could desire. They can now express themselves and show what they are capable of. Thank you for contributing with your End of Degree Project.

We would also like to thank the teachers and students in CEIP Seis do Nadal, particularly Ángeles, for been so welcoming and giving us an opportunity to try our virtual keyboard.

\section{REFERENCES}

[1] American Speech-Language-Hearing Association (ASHA). "Augmentative and Alternative Communication." On-line resource seen Dec. 2008 http://www.asha.org/public/speech/disorders/AAC.htm

[2] American Speech-Language-Hearing Association (ASHA). 1991. "Report: Augmentative and alternative communication." Asha,33(Suppl.5), 9-12

[3] Matas, J., Mathy-Laikko, P., Beukelman, D., \& Legresley,K, 1985. "Identifying the Non-speaking Population: A Demographic Study." Aumentative and Alternative Communication, 1, 17-31

[4] Blackstone, S.W.(Ed.). 1986. "Augmentative and Alternative Communication: Management of Severe Communication Disorders in Children and Adults". Paul H. Brookes, Baltimore.

[5] Boardmaker [Computer Software] 1995.Mayer-Johnson Co. Solana Beach, CA.

[6] Hourcade, J., Pilotte, T.E., West, E., \& Parette, P. 2004. "A History of Augmentative and Alternative Communication for Individuals with Severe and Profound Disabilities". Focus on Autism and Other Developmental Disabilities, 19(4): 235-244.

[7] García, F.M., Vez, J.M y Carballo, J.M. 2008 "Diseño e Implementación de un Tablero de Comunicación Digital SAAC." en $\mathrm{M}^{\mathrm{a}}$ Dolores Hurtado Montesino y Francisco Javier Soto Pérez (Coord.) La igualdad de oportunidades en el mundo digital. Murcia: Universidad Politécnica de Cartagena, pp. 421-429

[8] S-J. Liebowitz, S.E. Margolis, "The Fable of the Keys" Journal of Law \& Economics, University of Chicago Press, vol 33 (1), pp 1-25, 1990

[9] Fletcher P,. "Secret and Urgent: the Story of Codes and Ciphers" Blue Ribbon Books, 1939, pp. 254-255 